\title{
Murder by Death: Renfield Syndrome
}

\author{
Authors: $\quad$ Robert M. Kaplan \\ Submitted: $\quad$ 10. January 2022 \\ Published: $\quad$ 11. January 2022 \\ Volume: 9 \\ Issue: 1 \\ Affiliation: University of Wollongong, Australia \\ Languages: \\ Keywords: \\ Categories: \\ English \\ Clinical vampirism, Renfield Syndrome, blood, DSM \\ Humanities, Social Sciences and Law \\ DOI: $\quad$ 10.17160/josha.9.1.798
}

Abstract:

What is a psychiatric disorder? How do you distinguish madness from normal behaviour? The nomenklatura of American psychiatry follow a be fruitful-and-multiply approach, with every edition of the DSM - the Diagnostic and Statistical Manual - proffering a dazzling array of new conditions. Where these disorders arise is a matter of contentious debate with a strong school of thought contending that they emerge, not from decades of careful clinical observation, but the exigencies of an organising committee with its accompanying politics. This is hardly a good way for a behavioural science to progress, but unwittingly perpetuates a postmodern trope where truth is a dubious entity.

\section{JOSHA Jumna ossemene. Humanities and Arts}




\title{
Murder by Death: Renfield Syndrome
}

\section{Robert M Kaplan}

Clinical Associate Professor, Graduate School of Medicine, University of Wollongong, Wollongong, Australia

\begin{abstract}
:
What is a psychiatric disorder? How do you distinguish madness from normal behaviour? The nomenklatura of American psychiatry follow a befruitful-and-multiply approach, with every edition of the DSM - the Diagnostic and Statistical Manual - proffering a dazzling array of new conditions. Where these disorders arise is a matter of contentious debate with a strong school of thought contending that they emerge, not from decades of careful clinical observation, but the exigencies of an organising committee with its accompanying politics. ${ }^{1}$ This is hardly a good way for a behavioural science to progress, but unwittingly perpetuates a postmodern trope where truth is a dubious entity.
\end{abstract}


These matters being what they are, it can be said with certainty that one described condition - Renfield Syndrome - will not make it into DSM-6. The condition was described by Richard Noll, a critical historian of psychology, in 1992 and what followed is a study in how modern science is shaped by social and cultural factors. ${ }^{2}$

\section{Features of the syndrome include:}

1. The compulsion to drink blood almost always has a strong sexual component associated with it.

2. Blood will sometimes take on an almost mystical significance as a sexualized symbol of life or power, and, as such, an experience of well-being or empowerment will be reported by those with Renfield's syndrome following such activities.

3. Persons with Renfield's syndrome are primarily male.

4. The blood-drinking compulsion is the defining characteristic of Re0nfield's syndrome. Activities such as necrophilia and necrophagia that do not have as their goal the drinking of blood are not to be considered aspects of this disorder.

Noll listed three phases in the syndrome.

Stage 1 is auto-vampirism: drinking one's own blood. This starts in childhood, the taste of blood from removing scabs is exciting and later sexually arousing. The true devotees progress to opening their veins and arteries to drink a steady stream of warm blood.

Stage 2 is zoophagia: eating living creatures, but specifically drinking their blood.

Finally, there is vampirism, the drinking of human blood, often associated with serial murder and a distinct sexual element. 
To start, who was the eponymous R. M. Renfield who took on new life in this fashion? R. M. Renfield exists only in fiction as the incarcerated lunatic in Bram Stoker's splendid Dracula (1897), the book that sparked a lasting vampire cult, not least in literature and movies.

Bram Stoker (1847-1912), came from an Irish medical family and the influence of his brother William Thornley, a prominent surgeon who also had appointments at the two Dublin asylums, is not hard to detect in his most famous work, Dracula, which sadly did not bring him the fame and fortune he desired.

We first meet Renfield at the private clinic in London run by Dr John Seward, a lunatic-asylum mad doctor. This was a time when mad doctors - often not doctors at all - were becoming alienists and, later, psychiatrists. $^{3}$

Seward, a doctor of his time, gives morphine and chloral to himself, his friends and his patients. Chloral hydrate, the first modern psychotropic drug, was synthesized by Justus von Liebig in $1832 .{ }^{4}$ Its synthesis was the opening stanza of the new pharmaceutical chemistry where drugs were produced in a laboratory, not derived from natural preparations. The public took to it with enthusiasm and the use of chloral as a sedative and hypnotic escalated at the end of the nineteenth century. In thoroughly modern fashion, Seward dictates his notes into a phonograph.

Seward diagnoses his patient Renfield as a 'zoophagous maniac':

R. M. Renfield, aetat 59.- Sanguine temperament; great physical strength; morbidly excitable; periods of gloom, ending in some fixed idea which I cannot make out. I presume that the sanguine ${ }^{5}$ 
temperament itself and the disturbing influence end in a mentallyaccomplished finish; a possibly dangerous man, probably dangerous if unselfish.

Renfield has zoophagia, a compulsion to eat insects, eat live animals or drink their blood. He starts with flies, progresses to Death's-head moth, then feeds the flies to spiders, and the spiders to birds. When denied a cat to accommodate the birds, he eats the birds himself.

This behaviour does not improve his state of mind, to say the least:

His moods change so rapidly that I find it difficult to keep touch of them, and as they always mean something more than his own wellbeing, they form a more than interesting study.

Renfield is put into a strait-waistcoat and chained to the wall in a padded room, another feature that was to be used in future psychiatric wards.

After the lovely Lucy Westenra (having spurned Seward) falls ill, Seward calls Professor Van Helsing, his old teacher from Amsterdam. While the materialist Seward is a an admirer of David Ferrier, Van Helsing, by contrast, follows the work of Charcot and Lombroso. ${ }^{6}$ He believed that hypnosis is related to telepathy and that Dracula was a kind of 'throwback'. They revive Lucy with blood transfusions - again, very modern treatment (but misguided as likely to cause a transfusion reaction) - but it is too late; Lucy is now a vampire.

Insane, Renfield maintains telepathic contact with his master Count Dracula who moved from Transylvania to the ancient mansion of Carfax, bringing his 'earth-boxes' with him. 
Renfield keeps trying to escape from hospital to meet Dracula, drawn by his offer: he will make him immortal by providing an endless supply of insects and rats as blood is the source of life. Renfield attacks Seward, cutting his arm and licking his blood drips from the floor. He is put in a straitjacket and chained to the wall in a padded room.

Beset by an un-vampiric attack of conscience, Renfield becomes concerned for the safety of Mina Harker. When Dracula throws him on the floor, severely injuring him, Van Helsing performs a craniotomy on Renfield dramatic surgery indeed. ${ }^{7}$ Faced with the prescribed anti-vampire apparatus of crucifixes and sacramental wafers of bread (but sadly no garlic), Dracula flees to Renfield's room to break his neck. The last sight we have of Renfield is a bat rising out of the window of his room, flapping westward in approved fashion -a closing scene beloved of movie makers.

The existence of Renfield Syndrome, aka clinical vampirism, raises the epistemological dilemma that ever dogs psychiatry: What is a psychiatric disorder? What happened was an example of the law of unintended consequences. Following Noll's description, several papers emerged describing clinical cases that met the criteria for the syndrome, only to prompt Noll to state that it had really been intended as a joke. Both amused and horrified by the monster he had created, Noll made it clear that he had written about the syndrome on impulse and it was entirely ironic (fang-incheek?). ${ }^{8}$ But monsters tend to have a life of their own. Stranger things have happened. Noll had, however, opened a Pandora's box. Was it entirely accidental or does Renfield Syndrome actually exist?

Gothic fantasy notwithstanding, this brings us back to vampirism as a clinical disorder. 
Psychiatric interest in blood-drinking behaviours associated with sexual pleasure has been around since 1892 with the work of the splendidly named Austrian psychiatrist Richard Fridolin Joseph Freiherr Krafft von Festenberg auf Frohnberg, genannt von Ebing, more prosaically known as Baron Richard von Krafft-Ebing. A believer in the theory of degeneration, Krafft-Ebing wrote Psychopathia Sexualis, the only medical book to have pornographic status. In the process, Krafft-Ebing gave the world the term 'sado-masochism', making him pinup boy for the bondage set. Among his cases was a 24-year-old vinedresser who murdered a twelve-year-old girl in the woods, going on to drink her blood, mutilate her genitals, eating part of her heart and burying the remains. Another man cut his arm for his wife to suck on before sex because it aroused her so strongly.

Psychiatrists, often all too uncritical as a group, took the bait and the result was the article by Regis Olry and Duane Haines' paper Renfield's Syndrome: A Psychiatric Illness Drawn from Bram Stoker's Dracula in the Journal of the History of the Neurosciences. ${ }^{9}$ The myth of vampirism is in the best of health, although the etiology was unknown. The diagnostic criteria were met by the serial killer Richard Trenton Chase who kept asking for blood while in prison. ${ }^{10}$ The authors, apparently unaware of Noll's confession, cited van den Bergh and Kelly who stated that "The syndrome and fantasies of vampirism are more frequent and important than their relative absence in the literature would suggest". ${ }^{11}$ The etiology of the syndrome, however, was unknown.

South Africa, a country perhaps not as far away in the imagination from Transylvania as it may seem, played a part in initiating psychiatric vampirism, exposing a hitherto unknown African Gothic. In 1983 Helphill and Zabow at the Valkenberg Hospital in Cape Town described a series of three patients showing clinical vampirism as a recognizable, although rare, 
entity characterized by periodic compulsive blood drinking, affinity with the dead and uncertain identity. ${ }^{12}$ The vampirists cut themselves from childhood, drank their own, other human or animal blood, dreamed of bloodshed, associated with the dead, and had shifting identities. Some selfcutters are auto-vampirists; females were not likely to assault others for blood, but males are potentially dangerous. Vampirism should be looked for in violent criminals who are self-mutilators, but there was no specific treatment.

Following up on this study, Herschel Prins, a distinguished forensic social worker originally from South Africa, categorised vampirism as a clinical disorder. Prins pondered whether, at some level, blood-sucking is an extension of the ubiquitous love bite; an idea, in this day and age of sexual extremism, might not be as extreme as it seems.

Psychiatric disorders associated with vampirism include schizophrenia, psychopathic personality disorder and mental retardation. Psychoanalysts attribute the phenomenon to lack of infantile nourishment (but they would, wouldn't they? $\left.{ }^{13}\right) . .^{1415}$ This remains an untestable hypothesis.

In forensic terms, vampirism can be associated with such irenic activities as necrophilia (sexual abuse of corpses) and necrophagia (cannibalism, not eating at a global fried chicken chain). Some of the most notorious serial killers would attain this triad, but it is extremely rare; at recent count, it would apply to serial killers Peter Kürten and Richard Trenton Chase who drank the blood of the people they murdered. ${ }^{16}$

Never far behind with ghastly crimes, Australia's most notorious contribution to the field is Tracey Wigginton who killed Edward Baldock 
in 1989, supposedly to drink his blood. ${ }^{17}$ However, while she later admitted to the brutal stabbing, unsurprisingly she always denied drinking blood. In 2003, 28 year-old male prostitute Shane Chartres-Abbott was charged with raping and attacking a woman whose tongue he bit off, telling her he was a vampire who needed to drink blood. ${ }^{18}$ While awaiting trial, he was shot and killed in circumstances which remain unclear, preventing the Australian justice system from nailing its first dinky-di true-blue vampire.

Showing that the heart of darkness still beats in Africa, allegations of vampire attacks in Malawi in late 2002 and early 2003 led to mobs stoning one person to death and attacking at least others, including Governor Eric Chiwaya, on the belief that the government was colluding with vampires, possibly closer to the truth than anyone could imagine. ${ }^{19}$

The vampire myth has also been taken up by the political class, specifically on the left. Anyone representing big money or banking soon earns the approbation of representing the parasitic class. Karl Marx, never one for restraint in his rhetoric, described capitalism as "dead labour which, vampire-like, lives only by sucking living labour, and lives the more, the more labour it sucks". This prescience clearly anticipates the experience of dealing with a modern telco.

It is human blood that holds a unique attraction for vampires. Its special status goes back to the first human societies and blood sucking turns up in most of the cultures that followed. Dietary restrictions in Judaism and Islam regarding the blood of slaughtered animals reflect a similar preoccupation and the anti-Semitic blood libel may have arisen from this. The Christian Eucharist has been interpreted as a ritualised drinking of blood. 
Blood, as well as other body substances, has been held since antiquity to have special properties (scatatherapeutic). ${ }^{20}$ Urine, semen and even faeces were also believed to have healing properties for a range of complaints. The ultimate manifestation of this was the belief that the semen ejaculated when a man was hanged was especially powerful - but if it hit the ground a mandrake plant would grow.

Rituals involving blood were common in the Old Testament. The ancient Greeks would threaten to drink their enemy's blood. The vampire myth was not long in following, commencing with blood-sucking ghosts and bats. It morphed into dead people who returned from the grave to suck the blood of the living. From this evolved the condign rituals to protect oneself from their depradations - a silver cross, a ring of garlic, a wooden stake through the heart and so on.

In Europe the vampire myth peaked in the 18th century, facilitated by regular epidemics. It was not unknown for victims of plague to be buried prematurely, only to return home later in a less than sanguine frame of mind, hence the belief in their "un-dead" nature.

The vampirism cult was especially prevalent in Eastern Europe and the Balkans. Here arose the most important mythic figure: Vlad the Impaler, a $15^{\text {th }}$ century Wallachian nobleman whose cruelty earned him the epithet of Count Dracula (dragon or devil). The names varied with the location: shtriga in Albania; vrykolakas in Greece; and strigoi in Romania, to mention but a few.

Vampires are revenants of evil beings, witches or suicide victims, but usually arise from a malevolent spirit capturing a corpse or by being bitten 
by a vampire. Mass hysteria led to corpses being staked and people (usually on the basis of score-settling) being accused of vampirism with an inevitable outcome.

The belief that vampires (or vampyres in Gothic terms) were pale entities that had to avoid sunlight facilitated the tenebrous environment in which they flourished. It led to speculation that they had congenital erythropoietic porphyria $^{21}$ or pellagra ${ }^{22}$ but there was, in reality, no basis for this. Schemes ranging from the crude to the elaborate were designed to identify vampires and to eliminate them from the world of the living. Cadavers were unearthed, the head severed and placed between the feet, the heart was also boiled in oil and dissolved in vinegar. The most popular response was to impale the vampire through the heart on a wooden stake. Sometimes a priest was called on to shoot the vampire with silver bullets. Garlic and the crucifix were considered effective apotropaics (protective measures against evil), as were wild rose, hawthorn plant and mustard seeds.

The extent to which vampire terror can take over people should not be underestimated. In 1978 a dead man was found in a heavily barricaded room, having choked to death on a clove of garlic - why couldn't he have worn it around his neck like the rest of us?

Vampire writing kicked off in 1819 with The Vampyre by John Polidori, followed by many others. ${ }^{23}$ To Stoker goes the credit for putting it firmly on the cultural map. He is thought to have based his character on Vlad the Impaler $^{24}$ - hence the Balkan location - and the thoroughly malevolent lesbian murderess Countess Bathory who drank the blood of her young female victims to preserve her beauty. Her necrophilia notwithstanding, speculation continues as to whether the Gabor sisters are descended from her. 
It was not too long before the movies picked up on the topic; the first vampire movie Nosferatu was made in 1922; the central character, based in Romania, combined blood sucking with rape. After this, the suitably Hungarian Bela Lugosi made the role his own.

The public legend of vampirism will fly and fly with writers and filmmakers always ready to keep it aloft. The media never miss an opportunity to pin the label on a ghastly murderer whenever there is a lot of blood involved in the killer.

Many of the famous forensic cases alleged to be associated with vampirism were anything but that, although it could be used as a last-ditch defence by the accused to make them seem insane and therefore unable to be found guilty - notoriously by Haigh in the acid-bath case. ${ }^{25}$ Several cases have been described where death of the victim did not occur and, it should be noted, auto-vampirism is more predominant in women. Autohaemofetishism is sexual pleasure derived from the sight of blood drawn up in a syringe, a behaviour under-estimated in addicts.

Renfield Syndrome is an entirely fictional condition that only exists in the mind of those who ignore the dictum that all illness is ultimately social. That actual cases of clinical vampirism are remarkably rare is beside the point. The vampire phenomenon, on the other hand, is deeply embedded in the human need to have a romantic enemy to haunt us. The vampire's kiss is the ultimate embrace and, for all the shock-horror that we so enjoy, who has not, at some time or other, wondered just how much fun it could be to soar off into the sky like that? 
In Love at first bite we find that George Hamilton, the man born under a sun lamp, and the vulpine but nubile Susan St James, as future vampire Cindy Sondheim, had it just right:

Cindy Sondheim: Oh, this isn't so hard. I think I'm going to love immortality.

Count Dracula: There is one small disadvantage. We can only live by night.

Cindy Sondheim: Oh, that's all right with me. I mean, I could never really get my shit together till 7:00, anyway.

These matters being what they are, it can be said with certainty that Renfield Syndrome will not make it into DSM-6.

Robert M Kaplan

Austinmer December 2021.

${ }^{1}$ Kaplan RM. Current Psychiatry and its discontents. Academia.edu Letters. https://www.academia.edu/44195459/Current Psychiatry and its Discontents. Accessed on 23/11/2021. 
${ }^{2}$ See: Noll, Richard (1992). Vampires, Werewolves, and Demons: Twentieth century reports in the psychiatric literature. Brunner / Mazel Publications. ISBN 0-87630-632-6via Google Books. "Vampires, Werewolves, and Demons". academia.edu. Accessed $24 / 11 / 2021$.

${ }^{3}$ Bhugra D, Gupta S. Alienist in the 21st century. Asian J Psychiatr. 2011 Jun;4(2):92-5.

${ }^{4}$ Relationships between synthetic dyes and drug entities .pdf https://www.utpjournals.press/doi/pdf/10.3138/cbmh.1.2.1

${ }^{5}$ The reference to 'sanguine' heralds the haematophilia that was to follow.

${ }^{6}$ Fiona Subosky. Dracula (1897), Bram Stoker. The British Journal of Psychiatry (2009) 195, 263.

${ }^{7}$ Craniotomy arises from trepanning, the first known form of neurosurgery, a procedure going back several thousand years.

${ }^{8}$ Noll, Richard (October 2013). "Renfield's Syndrome, or, How I (unintentionally) created a monster". Archived from the original on 2016-03-04. Accessed 26/11/2021.

R von Krafft-Ebing; Charles Gilbert Chaddock. Psychopathia sexualis Philadelphia, London, F.A. Davis Co., 1892.

${ }^{9}$ Régis Olry \& Duane E. Haines (2011) Renfield's Syndrome: A Psychiatric Illness Drawn from Bram Stoker's Dracula , Journal of the History of the Neurosciences: Basic and Clinical Perspectives, 20:4, 368-371

${ }^{10}$ Markman R, Bosco D (1993): Alone with the Devil: Psychopathic Killings that Shocked the World. London, BCA, page 191.

${ }^{11}$ Bergh RL vanden, Kelly JF (1964): Vampirism: A review with new observations. Arch Gen Psychiat 11: 543-547.

${ }^{12}$ Hemphill RE, Zabow T. Clinical vampirism. A presentation of 3 cases and a reevaluation of Haigh, the 'acid-bath murderer'. S Afr Med J. 1983 Feb 19;63(8):278-81.

${ }^{13}$ Why then do they not bite breasts, rather than necks?

${ }^{14}$ Roger Luckhurst. Dracula and Psychology in: The Cambridge Companion to Dracula. Cambridge University Press, November 2017; See cambridge.org/core/books/abs/cambridge-companion-to-dracula/dracula-and psychology/DFB07B188860BAB32806C29CACDB57AE. Accessed on 23-112021.

${ }^{15}$ Ernest Jones. On the Nightmare. New York: Liveright, 1950), 110.

${ }^{16}$ See: "Peter Kürten: German Serial Killer". Britannica.com. 26 November 2006. Retrieved 24 November 2021; and, Bovsun, Mara (January 2, 2010). "Just crazy for blood: Richard Trenton Chase, a.k.a. the Vampire of Sacramento". New York Daily News. Accessed 24 November 2011.

${ }^{17}$ Sutton, Candace (10 August 2021). "Lesbian vampire killer drank victim's blood". news.com.au - Australia's leading news site. Retrieved 19 November 2021.

${ }^{18} \mathrm{https}$ ://www.mamamia.com.au/shane-chartres-abbott-vampire-gigolo/. Accessed on 27/11/2021.

${ }^{19} \mathrm{http}: / /$ edition.cnn.com/2003/WORLD/africa/01/11/offbeat.politican.vampir e/. Accessed on 27/11/2021.

${ }^{20}$ Kaplan RM. Forensic feuilleton: body fluids are the best. Medical Republic, 24 January 2019. 
${ }^{21}$ Cox AM. Porphyria and vampirism: another myth in the making. Postgrad Med J, 1995, vol. 71 (pg. 643-4).

${ }^{22}$ Hampl JS, Hampl WSIII. Pellagra and the origin of a myth: evidence from European literature and folklore. JR Soc Med, 1997, vol. 90 (pg. 636-9).

${ }^{23} \mathrm{https} / / /$ www.bl.uk/collection-items/the-vampyre-by-john-polidori. Accessed on 27/11/2021.

${ }_{24}$ Treptow, Kurt W. (2000). Vlad III Dracula: The Life and Times of the Historical Dracula.

${ }^{25}$ Hall, Angus (1976). Crimes of Horror. Phoebus Publishing. p. 12. 